\title{
Incidente de Resolução de Demandas Repetitivas e sua Permeabilidade à Autocomposição
}

\section{Urban Mobility as a formo $f$ effectiveness of the Social Function of public transport and concretion of Social Rights}

\author{
Humberto Dalla Bernardina de Pinho ${ }^{l}$ \\ Ludmilla Camacho Duarte Vidal ${ }^{2}$
}

\begin{abstract}
RESUMO:
O presente artigo objetiva tratar do Incidente de Resolução de Demandas Repetitivas (IRDR) no tocante a sua permeabilidade ao uso das ferramentas de solução consensual de conflitos. Para a averiguação sobre a viabilidade do consenso no IRDR, partiremos do panorama atual do Direito Processual Civil contemporâneo, palco cooperativo e satisfatório para a busca do diálogo profícuo, no qual se percebe uma confluência de institutos promissores rumo ao aprimoramento do sistema jurisdicional brasileiro. Mais adiante, abordaremos o modelo processual alemão, em que há previsão na Kapitalanleger-Musterverfahrensgesetz - KapMuG sobre a admissibilidade de transação no Musterverfahren. Também será analisado o settlement class action previsto na Rule 23, subdivisão (e) (2) das Federal Rules of Civil Procedure, principalmente nos pontos trazidos pela recente reforma de dezembro de 2018. Demonstraremos, em seguida, o hiato do sistema brasileiro acerca da matéria, jogando luzes em parâmetros de controle dos acordos celebrados tanto nos processos sobrestados quanto na própria causa-piloto. Será atribuído destaque em possíveis critérios para a homologação judicial da negociação no IRDR, como a existência de audiência pública após prévia notificaçãoadvertência individualizada dos interessados, a adoção dessa notificação por meios também eletrônicos e a observância de uma aceitação mínima ou uma rejeição máxima como parâmetro para se aferir a validade e legitimidade da proposta, o que na Alemanha corresponde ao percentual de $30 \%$ dos interessados no incidente, conforme é previsto da $\mathrm{KapMuG}$.
\end{abstract}

\section{PALAVRAS-CHAVE:}

Acordo; IRDR; CPC; homologação.

\begin{abstract}
:
This paper aims to deal with the Incident of Resolution of Multiple Actions (IRDR) regarding its permeability to the use of the ADR mechanisms. In order to investigate the feasibility of the consensus in the IRDR, we will start from the current panorama of contemporary Civil Procedural Law, a cooperative and satisfactory stage for the search for a fruitful dialogue, in which a confluence of promising institutes towards the improvement of the Brazilian jurisdictional system can be perceived. Further on, we will turn to the German procedural

\footnotetext{
${ }^{1}$ Professor Titular de Direito Processual Civil (UERJ, Estácio e Ibmec). Martin-Flynn Global Law Professor (University of Connecticut School of Law). Professor Emérito e Diretor Acadêmico da FEMPERJ. Membro do Ministério Público do Estado do Rio de Janeiro.

${ }^{2}$ Mestre e Doutoranda em Direito Processual (UERJ). Pesquisadora visitante da Universidade Paris 1 PanthéonSorbonne. Pesquisadora da CAPES. Advogada.
} 
model, which is foreseen in the Kapitalanleger-Musterverfahrensgesetz - KapMuG on the admissibility of a transaction in Musterverfahren. The settlement class action envisaged in Rule 23, subdivision (e) (2) of the Federal Rules of Civil Procedure will also be analyzed, especially in the points brought about by the recent reform of December 2018. We will then demonstrate the Brazilian system's light of the parameters of control of the agreements entered into in the case itself. It will be highlighted in possible criteria for the judicial homologation of the negotiation in the IRDR, such as the existence of a public hearing after previous notification individualized warning of the interested parties, the adoption of such notification by electronic means and the observance of a minimum acceptance or a maximum rejection as in order to assess the validity and legitimacy of the proposal, which in Germany corresponds to the 30\% of those interested in the incident, as provided for in the KapMuG.

KEYWORDS:

Settlement; multiple actions; civil procedure; homologation.

\section{INTRODUÇÃO}

O desafio que nos move no presente estudo é remover as barreiras que separam a autocomposição e o Incidente de Resolução de Demandas Repetitivas (IRDR). Em uma primeira mirada, poderia soar estranha a tentativa de se acomodar "acordo" e "julgamento de casos repetitivos" num mesmo estudo.

Isso porque o principal objetivo do IRDR reside na formação da tese jurídica a ser aplicada aos processos judiciais pendentes e, ato contínuo, na produção de um precedente judicial obrigatório, o qual vinculará a solução dos casos futuros. A formação da tese no IRDR oferece segurança jurídica e previsibilidade para as relações, pois se torna possível antever a postura do judiciário nos casos que versarem sobre a mesma questão comum. Além disso, a fixação da tese imprime isonomia na interpretação e aplicação do direito, tendo em vista que a atuação do Poder Judiciário é conduzida pelas razões de decidir do processo anterior que comporte os mesmos motivos determinantes. 
Nesse sentido, a incompatibilidade inicial estaria na compreensão equivocada de que, ao se conceber espaços à consensualidade no âmbito de uma causa-piloto, ${ }^{3}$ por exemplo, estaria sendo evitada a formação de um precedente judicial e as respostas por ele buscadas, como a atribuição de maior segurança jurídica no desempenho da função jurisdicional e o respeito à igualdade enquanto unidade do Direito.

No ponto, se faz oportuno lançar a seguinte indagação: seria a consensualidade, vis-àvis, ideia contrária ao espírito do Incidente de Resolução de Demandas Repetitivas? Ou melhor dizendo: existiria espaço, no IRDR, para manifestações da autonomia privada, desde que respeitados certos "limites do consenso"4 ? Caso positivo, seria possível pensar em um modelo de negociação na perspectiva do $\operatorname{IRDR},{ }^{5}$ de maneira a equilibrar a ingerência de ambos institutos tão promissores ao aprimoramento do sistema jurisdicional e de promoção dos Direitos Fundamentais?

Antes de entrarmos na temática propriamente dita, parece necessário tecer algumas considerações.

Compreender o Incidente de Resolução de Demandas Repetitivas da forma com a qual nos impõe ser mais adequada é situá-lo dentro de três importantes sistemas, a saber: (i) julgamento de casos repetitivos; (ii) formação de precedentes vinculantes e; (iii) coletivização de demandas, a partir da fixação da tese jurídica no processo-piloto. Assim, as demandas sujeitas ao processamento do IRDR podem versar tanto sobre direitos individuais heterogêneos quanto direitos individuais homogêneos ${ }^{6}$. Nesse último caso, por serem direitos materiais

\footnotetext{
${ }^{3}$ Conforme mencionado adiante, iremos analisar a possibilidade de acordo no bojo de uma causa-piloto. Pretendemos examinar as demais possibilidades de acordo dentro da sistemática do IRDR posteriormente, em outra oportunidade.

${ }^{4}$ PINHO, Humberto Dalla Bernardina de. Jurisdição e Pacificação: limites e possibilidades do uso dos meios consensuais de resolução de conflitos na tutela dos direitos transindividuais e pluri-individuais, Curitiba: CRV, 2017, p. 280.

${ }^{5}$ MENDES, Aluísio Gonçalves de Castro. Incidente de Resolução de Demandas Repetitivas - Sistematização, análise e interpretação do novo instituto processual. Rio de Janeiro: Forense, 2018, p. 251-252

${ }^{6}$ Acerca da conceituação e distinção entre essas modalidades de direito, veja-se: PINHO, Humberto Dalla Bernardina de Pinho. Direito individual homogêneo - uma leitura e releitura do tema. Revista Juris Poiesis, Rio de Janeiro, v. 6, 2004, p. 216.
} 
acidentalmente coletivos, como preconizou José Carlos Barbosa Moreira ${ }^{7}$, a sua relevância social clamaria por uma maior rede de proteção.

Portanto, a síntese da problemática que se descortina corresponde aos seguintes questionamentos: o acordo judicial firmado em sede de IRDR, quando realizado no processo paradigma, ou seja, no processo representativo da controvérsia, obstaria a formação do precedente judicial?

Além disso, se a causa-piloto versar sobre direitos individuais homogêneos, a consensualidade poderá atingir o próprio direito material questionado? Diante desse panorama, qual deve ser a postura mais adequada do Poder Judiciário nessa negociação?

Ao adotarmos a possibilidade de autocomposição no IRDR como possível e inclusive estimulável, ainda devemos questionar, por consequência, se haveria ou não a vinculação daqueles interessados na formação da tese em relação aos termos da negociação firmada e, ademais, como essa vinculação se efetivaria na prática.

Com efeito, o presente estudo objetiva enfrentar esses questionamentos colocados, de modo a se constatar que o Incidente de Resolução de Demandas Repetitivas é perfeitamente permeável às instâncias do consenso. Negar essa importante premissa seria manifestar completa incompreensão dos influxos trazidos pelo Direito Processual Civil contemporâneo, deveras influenciado pela reconhecida política pública de fomento às práticas autocompositivas e de pacificação social, sob a égide do CPC de 2015.

\footnotetext{
${ }^{7}$ BARBOSA MOREIRA, José Carlos. Tutela jurisdicional dos interesses coletivos ou difusos. Temas de Direitos Processual Civil - 3. série. São Paulo: Saraiva, 1984, p. 195-197; BARBOSA MOREIRA, José Carlos. A ação popular no Direito Brasileiro, como instrumento de tutela jurisdicional dos chamados interesses difusos. Revista de Processo, São Paulo, n. 28, p. 7-19, out./dez. 1982, p. 9.
} 


\section{PANORAMA ATUAL E PREMisSas ESSENCIAIS: A CONFluENCIA DE INSTITUTOS PROMISSORES DO CÓDIGO DE PROCESSO CIVIL}

O Código de Processo Civil de 2015 adveio para autenticar uma nova mentalidade de como pensar e operacionalizar o Processo Civil brasileiro. Consoante referido nas linhas anteriores, o fomento à autocomposição é alçando na qualidade de verdadeira política pública.

O legislador impõe aos operadores do direito o comprometimento com a priorização da consensualidade em detrimento da imposição da decisão final pelo Estado-juiz. Podemos afirmar que a busca pelo consenso se revela uma tendência não só no Brasil como no mundo ${ }^{8}$ em virtude do elevado grau de legitimidade do desfecho alcançado pelos acordantes, da eficiência propiciada ao sistema judicial como um todo, porquanto mais desafogado e, principalmente, pela retomada do empoderamento daqueles que são os maiores interessados da demanda: as partes.

Atualmente, percebe-se que o alcance das práticas negociais atingiram a própria produção da norma processual, não mais restrita ao direito vigente de base unicamente legislada. ${ }^{9}$ Com efeito, além da norma jurídica processual de matriz legislativa, é admissível a produção da norma processual convencionada,${ }^{10}$ mediante a negociação das partes, desde que

\footnotetext{
${ }^{8}$ En conclusion, le système des modes alternatifs de règlement des conflits est donc pluriel, comme l'est le système plus général de justice dans lequel ces modes s'inscrivent aux côtés de techniques traditionnelles de solution judiciaire des litiges". CADIET, Loï. L'arbitrage et l'evolution contemporaine des modes de reglement des conflits. In: Revista Eletrônica de Direito Processual, vol. 12, n.12, 2013, pp.446-462, p.462; PICARDI, Nicola. La giurisdizione all'alba del terzo millennio. Dialettica, Diritto e Processo. A cura di Alessandro Guiliani e Nicola Picardi, v.3. Milano: Giuffrè Editore, 2007, p.174 et seq.; GUINCHARD, Serge et al. Droit processuel: droits fondamentaux du procès, 8.ed. Paris: Dalloz, 2015, Section 1; Section 2 et Section 3, p.1.312 et seq.

${ }^{9}$ CADIET, Loïc. Le spectre de la société contentieuse. Droit civil, procédure, linguistique juridique. Écrits en Hommage a Gérard Cornu. Textes réunis et publiés par Jean Beauchard et Pierre Couvrat. Paris: P.U.F, 1994, p. 50; Les conventions relatives au procès en droit français. Sur la contractualisation du règlement des litiges. In: Rivista Trimestrale di Diritto e Procedura Civile. Numero speciale: accordi di parte e processo. Milano: Giuffrè, 2008, p.9.

${ }^{10}$ As atuais luzes lançadas nos negócios jurídicos processuais, instrumento que imprime outra dimensão às fronteiras negociais no Processo Civil, resultam da necessidade novos espaços de liberdade na condução do processo cooperativo. Reconhece-se que o ordenamento brasileiro demonstra ser compatível com a convencionalidade mesmo em espaços penetráveis por interesses públicos. GRECO, Leonardo. Os atos de disposição processual: primeiras reflexões. In: Os Poderes do Juiz e o Controle das Decisões Judiciais: Estudos em Homenagem à Professora Teresa Arruda Alvim Wambier. São Paulo: Revista dos Tribunais, 2008; VIDAL, Ludmilla Camacho Duarte. Convençôes Processuais no paradigma do Processo Civil Contemporâneo. Rio de Janeiro: Gramma Editora, 2017. CABRAL, Antonio do Passo. Convenções Processuais. Salvador: Juspodivm, 2016; CADIET, Loïc. Propos introductif; "faire lien”. In: La contractualisation de la production normative. Sous
} 
observados os critérios elencados no artigo 190 do Código de Processo Civil e outros limites colocados pelo ordenamento jurídico vigente. ${ }^{11}$

Os sopros inovadores desses novos tempos convergem com a ideia de abrangente negociabilidade, seja quanto ao próprio fundo de direito (acordos materiais) versado na causa, ou a respeito da formatação e da disposição das situações jurídicas processuais (acordos processuais). De fato, o importante é percebermos, dentro desse cenário, toda a potencialidade da tendência de se fomentar a abertura das esferas de consenso, ${ }^{12}$ cenário incrementado com a Lei de Mediação Brasileira (Lei 13.140/2015), que consolida o entendimento de que há espaços de negociação ampliada inclusive em sede de litígios que digam respeito a direitos individuais indisponíveis, no entanto, transacionáveis. ${ }^{13}$

A impossibilidade de transação de direitos gravados com o signo da indisponibilidade nos parece que deve ser considerada em caráter de exceção. Para nós, em estudo já publicado, estes seriam os direitos da personalidade stricto sensu e os difusos sobre os quais não se consegue identificar sua titularidade com uma precisão mínima. ${ }^{14}$

De modo geral, a transação em direitos indisponíveis, aplicada aos direitos individuais e aos direitos coletivos - sejam essencial ou acidentalmente coletivos - exige prévia participação do Ministério Público e posterior análise pelo Poder Judiciário em decisão homologatória.

\footnotetext{
la direction de Sandrine Chassagnard-Pinet, David Hiez. Paris: Dalloz, 2008; CAPONI, Remo. Autonomia privata e processo civile: gli accordi processuali. Rivista Trimestrale di Diritto e Procedura Civile. Numero speciale: accordi di parti e processo. Milano: Giuffrè, 2008; CARPI, Federico. Introduzione. Rivista Trimestrale di Diritto e Procedura Civile. Numero speciale: accordi di parti e processo. Milano: Giuffrè, 2008; MULLER, Ivone. Le contrat judiciaire en droit privé. These pour le Doctorat en Droit. Paris: Université de Paris I Panthéon-Sorbonne, 1995; GODINHO, Robson Renault. Negócios processuais sobre o ônus da prova no novo código de processo civil. In: WAMBIER, Teresa Arruda Alvim; TALAMINI, Eduardo (coord.). Coleção Liebman. São Paulo: Revista dos Tribunais, 2015.

${ }^{11}$ GRECO, Leonardo. Instituições de processo civil - Introdução ao direito processual civil, vol.01, 5. ed. Rio de Janeiro: Forense, 2015, p.58 et seq.

12 DIDIER JR., Fredie; ZANETI JR., Hermes. Justiça multiportas e tutela constitucional adequada: autocomposição em direitos coletivos. ZANETI JR., Hermes; CABRAL, Trícia Xavier Navarro (Coord.). Justiça multiportas: mediação, conciliação, arbitragem e outros meios de solução adequada para conflitos. Coleção grandes temas do novo CPC. Coordenação geral: Fredie Didier Jr. Salvador: Juspodivm, 2017.

${ }^{13}$ GAVRONSKI, Alexandre Amaral. Autocomposição no novo CPC e nas ações coletivas. ZANETI JR., Hermes (Coord.) Processo Coletivo. Coleção repercussões do novo CPC. Coordenador geral: Fredie Didier Jr. Salvador: Juspodivm, 2016.

${ }^{14}$ O estudo é: PINHO, Humberto Dalla Bernardina de; VIDAL, Ludmilla Camacho Duarte. Primeiras Reflexões sobre os Impactos do novo CPC e da Lei de Mediação no Compromisso de Ajustamento de Conduta. In: Revista de Processo, vol. 256. São Paulo: Revista do Tribunais, 2016.
} 
Percebe-se que o controle judicial será imperioso para se aferir a legitimidade e validade da proposta.

Resgatando a análise do CPC/2015 no tocante à confluência de institutos promissores, cumpre destacar que este se voltou para três palavras de ordem: adequação, flexibilização e eficiência. $^{15}$

A adequação seria um patamar mais elevado em relação ao degrau da efetividade, pois indica a escolha do caminho disponível que corresponda, satisfatoriamente, aos interesses envolvidos na demanda. ${ }^{16}$ Várias ferramentas são possíveis de utilização, já que potencialmente efetivas, porém uma delas será mais adequada. ${ }^{17}$ A flexibilização é buscada pelo legislador em vários momentos, o qual, no intento de galgar maior sintonia com os preceitos constitucionais, prioriza a simplificação do procedimento, criando condições para desfechos mais eficientes e ajustados à realidade da causa.

A eficiência perfaz, outrossim, um dos desígnios da ordem processual constitucional, que busca o máximo de aproveitamento do processo sob uma perspectiva sistêmico-racional para que o direito, construído e aplicado, assim como é escrito um romance em cadeia, apresente coerência e integridade em si mesmo. Nesse panorama, a sistematização dos precedentes judiciais pelo Código de Processo Civil cumpre papel salutar e promissor ao aprimoramento da atividade jurisdicional.

${ }^{15}$ Sobre os atuais motes do direito processual civil brasileiro, na Exposição de Motivos do Anteprojeto do CPC/2015 foi concedido destaque à celeridade e à simplificação procedimental, perseguindo-se cinco principais orientações: i) alcançar a sintonia expressa e implícita com a Constituição Federal; ii) buscar a simplificação do procedimento; iii) criar melhores condições para que sejam proferidas decisões mais eficientes e compatíveis com a realidade fática subjacente à causa; iv) extrair de cada processo o melhor rendimento possível e; v) imprimir maior grau organizacional do sistema jurisdicional, atribuindo-lhe maior coesão.

${ }^{16}$ Por exemplo, nos termos do artigo $1^{\circ}$, parágrafo único da Resolução n. 118 do Conselho Nacional do Ministério Público, consiste em dever do membro do Ministério Público a orientação ao cidadão sobre os mecanismos disponíveis. A íntegra da Resolução n. 118, editada em 27 de janeiro de 2015, a qual estabelece a política nacional de incentivo à autocomposição no âmbito da instituição ministerial, poderá ser consultada em: http://www.cnmp.gov.br/portal/resolucoes/6871-resolucao-118.

17 "Não obstante servir inadvertidamente como a pretensa cura para a tormentosa incapacidade jurisdicional numérica de solucionar os conflitos que lhe são submetidos (viés quantitativo, mas que macula a qualidade do resultado), estes mecanismos devem ser vistos na verdade, a partir de suas bases constitutivas e valorativas, o que assume expressiva importância quando é observado um caminhar na cena contemporânea em direção a institucionalização generalizada da mediação (como já faz com a conciliação) e sua agregação ao Poder Judiciário". PAUMGARTTEN, Michele. Os desafios para a integração das práticas conciliatórias no novo processo civil. In: Revista de Processo, n. 247. São Paulo: Revista dos Tribunais, p.479. 
Um dos relevantes instrumentos que propicia esse avanço é o Incidente de Resolução de Demandas Repetitivas. Por corresponder a um mecanismo de julgamento de questões comuns de direito, o objetivo que se cumpre é promover a consolidação de uma tese jurídica sobre a matéria controvertida nos processos em tramitação, dando origem à fomação de um precedente judicial vinculante, ${ }^{18}$ que será aplicado aos casos futuros. ${ }^{19}$

Na verdade, a ratio essendi do IRDR é produzir uma conclusão para além da tese a ser replicada nas outras demandas que versarem sobre a mesma questão jurídica. Sobre a submissão à questão comum (seja o opt out - exclusão - ou opt in - inclusão), a formação do precedente obrigatório independe de qualquer conduta das partes do processo originário ou dos interessados que se encontram com seus processos pendentes.

Desse modo, em razão da própria natureza do precedente judicial tão importante para a estabilização das relações e para a promoção da isonomia - igualdade para além do processo: “treat like cases alike” ${ }^{20}$-, não se concede aos interessados a opção de escolha sobre a submissão ou não à tese firmada. Essa situação, no entanto, se opera de modo distinto dentro da sistemática dos acordos firmados em IRDR, conforme será visto adiante.

O precedente judicial firmado possui efeitos não só em assegurar a aplicação da mesma ratio decidendi, como também influencia nas próprias técnicas de julgamentos, de modo a otimizar a atividade jurisdicional. Vejamos.

A definição da tese no IRDR autoriza, v.g., o julgamento liminar de improcedência do pedido (artigo 332, III do CPC), o julgamento monocrático de mérito dos recursos e de conflito de competência (artigo 932, IV “c” do CPC), a inaplicabilidade da remessa necessária quando respaldar a sentença (v. artigo 496, $\S 4^{\circ}$, III do CPC), a presunção de repercussão geral em recurso extraordinário quando a decisão recorrida proferida pelos tribunais lhe for contrária (artigo 1.035, §3º , II do CPC), a presunção de omissão para fins de cabimento dos embargos de

\footnotetext{
${ }^{18}$ Conceitualmente, o precedente consiste no pronunciamento judicial, proferido em um processo anterior, aplicado em decisão judicial prolatada em processo anterior, a qual comporta os mesmos motivos fáticos e jurídicos determinantes, em que se utiliza, portanto, a mesma razão de decidir (ratio decidendi). CÂMARA, Alexandre. $O$ Novo Processo Civil Brasileiro. 2. ed. Rio de Janeiro: Forense, 2017, p.427.

${ }^{19}$ Percebe-se que isso fica muito claro no art. 985, incisos I e II sobre a decisão do IRDR.

${ }^{20}$ No Brasil, a expressão é utilizada por Hermes Zaneti Jr. em: Precedentes (treat like cases alike) e o novo código de processo civil: universalização e vinculação horizontal como critérios de racionalidade e a negação da jurisprudência persuasiva como base para uma teoria dogmática dos precedentes no Brasil. In: Revista de Processo, vol. 235/2014.
} 
declaração ao se considerar omissão a decisão que ignore o resultado do IRDR (artigo 1.022 do CPC).

Perceba-se que a formação da tese, por ser um precedente judicial de propósito, interfere no sistema de técnica processual como um todo, autorizando condutas específicas contempladas pela lei em reforço à força dos precedentes judiciais. Importante ressaltar ainda, que o impacto da tese do IRDR será tanto processual quanto extraprocessual, já que a previsibilidade propiciada evita o ajuizamento de demandas, além de representar um desestímulo ao prosseguimeto daquelas já deduzidas.

O próprio legislador inseriu no artigo $1.040 \S 2^{\circ}$ do CPC regra especialíssima de desistência da ação antes da prolação da sentença e após a notícia da decisão sobre a questão comum versada no IRDR. Diversamente da disciplina processual geral, a desistência da ação pelo autor nesses casos não só é permitida como estimulada ao dispensar o consentimento do réu e isentar o demandante de custas e honorários.

Por tudo que foi registrado, os precedentes judiciais são uma das principais promessas da nova ordem jurídica. Contudo, não com menos força emerge o sentimento de autorregramento dos cidadãos e o incentivo institucional a uma justiça mais pacificadora.

Conforme será demonstrado no próximo tópico, o acordo em IRDR, notadamente na causa-piloto, ainda que possa obstar a formação do precedente judicial para aqueles que aderirem à negociação a qual, eventualmente, venha a abarcar a totalidade da questão comum de direito, reforça, por outro lado, a autodeterminação dos indivíduos, que se encontram inseridos em um espaço de justiça coexistencial.

\subsection{Autocomposição no Incidente de Resolução de Demandas Repetitivas}

Após a demonstração do pano de fundo do presente estudo, cumpre analisar, de modo mais específico, a viabilidade do acordo no bojo da causa eleita como representativa da controvérsia (causa-piloto).

Não se enxerga maiores problemas na celebração de um ajuste de vontades quando o processo não tiver sido afetado, mas apenas sujeito à aplicação da tese, uma vez que esse processo não será instrumento para a formação de precedente. Essa possibilidade de acordo na 
sede de processo que não seja causa-piloto, mas que esteja submetido ao resultado do IRDR, encontra-se adstrita à esfera da autonomia privada dos celebrantes. Tratando-se de uma demanda individual não eleita como paradigma do incidente, o acordo guardaria, a princípio, eficácia inter partes.

Em contrapartida, se o processo não afetado for uma ação coletiva cuja pretensão se relacione à reparação a direitos individuais homogêneos, a questão já seria um pouco mais complexa.

Embora não seja nosso objeto de análise para o momento, compreendemos que tal questão exige certa revisitação dos limites objetivos dos acordos coletivos, assim como a consideração sobre a eficácia produzida para os indivíduos que não participaram da negociação.

Nesse quadro, a discussão tangencia o estudo sobre os limites do acordo coletivo, isto é, se a negociação sobre o fundo de direito material estaria restrita ou não ao que hoje se concebe como a margem negociável em sede dos termos de ajustamento de conduta.

Além disso, seria necessário averiguar a eficácia para aqueles que não participam do processo e, por conseguinte, indagar se realmente haveria a possibilidade da proposta de negociação se estender a todos os interessados na resolução da questão comum.

Independentemente desse instigante debate, o fato é que se essa demanda coletiva não for o processo paradigma do IRDR, o incidente continuaria sendo processado, não obstando a formação da tese jurídica e, automaticamente, do precedente judicial.

Portanto, até aqui podemos considerar duas possibilidades de acordo em IRDR. Ele poderá ocorrer no bojo de uma causa-piloto ou ainda nos processos que guardam a formação da tese jurídica, mas que não foram escolhidos como representativos da controvérsia.

A tendência é que a celebração do acordo sobre a questão jurídica comum ocorra na primeira situação, isto é, nos processos afetados, principalmente em virtude da ampla publicidade observada no IRDR, bem como do significativo espaço de debate e de participação social que este comporta. 
Nessa linha, os limites do consenso e o modo de concretização do acordo na prática deve guardar, preferencialmente, correspondência com a atuação dos órgãos competentes para a resolução do incidente. Ademais, acordos em demandas não afetadas podem gerar discussões infindáveis sobre a extensão subjetiva da negociação e, por consequência, questões a respeito da vinculação da proposta.

Tendo isso em vista, o Poder Judiciário e o legislador deverão criar estímulos para que as negociações sejam realizadas nos processos pilotos, podendo ser aderidas por todos os interessados. As propostas tendem a ser mais atrativas para ambas as partes, podendo acarretar ampla vinculação. Tal situação abre espaço para um formato processual mais estratégico, com base na perspectiva dos riscos envolvidos.

Por essas considerações, compreendemos que o acordo poderá ser uma adequada possibilidade, que se mais vantajosa sob a ótica dos seus celebrantes, afastaria a aplicação da tese para aqueles que aderirem à proposta, caso esta abarque a totalidade da questão jurídica comum.

Nesse aspecto, é preciso esclarecer: embora as partes da causa-piloto celebrem o acordo, o precedente será formado, aplicando-se analogamente a regra do artigo $976 \S^{\circ}$ do CPC sobre a desistência no IRDR. Dessa forma, o interesse coletivo justificaria o prosseguimento do incidente para a fixação da tese, com a formação do precedente. $\mathrm{O}$ fato é que, quanto maior for a adesão dos interessados ao acordo, possivelmente maior será a margem de negociação a respeito da questão discutida, já que os celebrantes não irão se submeter ao pronunciamento judicial vinculante.

Sistematicamente, o acordo poderá versar sobre direitos individuais homogêneos ou heterogêneos. Se forem objeto de análise os direitos individuais homogêneos, a causa-piloto poderá ser individual ou coletiva.

O ideal é que o acordo em IRDR seja realizado, em primeiro lugar e pelas razões já apresentadas, em uma causa-piloto, e em segundo lugar, que essa causa-piloto, por sua vez, seja uma ação coletiva, no caso de estar em jogo a discussão sobre direitos individuais homogêneos. 
Isso porque, em razão da publicidade e das diferentes técnicas de processamento que possuem, a proposta oferecida na causa-piloto será levada ao amplo conhecimento, a fim de que os interessados na resolução da controvérsia comum se manifestem a respeito da escolha da autovinculação (opt in) ou da autoexclusão (opt out).

Outro aspecto positivo é que o controle desses ajustes seria mais apurado, tanto pelo judiciário, em razão dos interesses pluri-individuais envolvidos, quanto pelos representantes adequados das classes envolvidas e, inclusive das próprias partes diretamente afetadas.

A prioridade de afetação de uma demanda coletiva como representativa da controvérsia no IRDR coaduna com o caminho trilhado pela jurisprudência atual dos tribunais superiores.

Nesse sentido, no julgamento do REsp 1.525.327 ${ }^{21}$, afetado ao regime dos recursos repetitivos, o Ministro Luis Felipe Salomão, relator e autor da tese vencedora, reconheceu que as ações coletivas guardam prevalência de julgamento em relação a todas as ações individuais que versarem sobre a mesma matéria de direito. Uma das razões de sustento dessa tese seria a de que o fato gerador comum proporciona uma defesa mais ampla dos prejudicados.

A orientação jurisprudencial indicada abre um caminho bastante promissor para as esferas de consenso no IRDR, já que traz os benefícios da negociação realizada em uma causapiloto correspondente a uma ação coletiva. $\mathrm{O}$ acordo adequado será o mais atrativo ao maior número de interessados, sob a perspectiva das partes e da própria eficiência do sistema judicial.

Quanto às partes, o réu temerá uma condenação macro-estrutural e por isso poderá propor concessões vantajosas aos demandantes, os quais, por sua vez, não tem qualquer garantia de que a tese final lhes seja favorável.

Quanto à eficiência do Poder Judiciário, ao mesmo tempo em que um bom acordo sobre a controvérsia jurídica repetitiva inibe a formação do precedente para os seus celebrantes, pacífica para esses a questão comum com alto índice de aceitabilidade, já que proveniente da

\footnotetext{
${ }^{21}$ No caso em análise, a $2^{\mathrm{a}}$ Seção do STJ, ao julgar o REsp 1.525.327 fixou a tese de que as demandas individuais de dano moral pela suposta exposição à contaminação ambiental, em virtude da exploração de jazida de chumbo no município de Adrianópolis no Estado do Paraná, deveriam ser suspensas até o trânsito em julgado das ações civis públicas em tramitação na Vara Federal Ambiental, Agrária e Residual de Curitiba. O julgamento foi noticiado pela Assessoria de Imprensa do STJ. Nesse sentido: https://www.conjur.com.br/2018-dez-26/stjsuspende-acoes-individuais-contaminacao-ambiental, acesso em 15 jan/2019.
} 
solução ajustada pelas próprias partes em um processo de tomada de decisão democrática e participativa.

Por conseguinte, ao identificar a ampla proporção que a negociação poderá alcançar, o réu tenderá, em linha de princípio, a se comportar de maneira mais aberta, de modo a propor concessões atrativas a fim de atingir o maior número possível de interessados. Os interessados, por outro lado, sem o conhecimento do que será decidido, poderão se valer de uma análise mais estratégica, de acordo com as contingências envolvidas na situação.

Parece ter sido esse o caminho escolhido no direito comparado.

Como mencionado nas linhas introdutórias, o nosso objetivo é aproximar consensualidade e julgamento de casos repetitivos. Visualizamos a possibilidade de encontro dos institutos mencionados, inclusive com relação ao Direito Processual Coletivo - quando se tratar de direitos individuais homogêneos -, sendo imperiosa certa delimitação das balizas pela observância de parâmetros de controle do consenso no âmbito do IRDR. Ressaltamos que tais critérios devem ser aferidos pelo Poder Judiciário no momento da homologação da negociação, quando examinar a viabilidade da proposta.

\section{FONTES DE INSPIRAÇÃO NO DIREITO ESTRANGEIRO: A POSSIBILIDADE DE ACORDO NO MUSTERVERFAHREN (KAPITALANLEGER- MUSTERVERFAHRENSGESETZ) E O SETTLEMENT (RULE 23 (E) F.R.C.P.)}

No presente tópico serão observados dois institutos alienígenas. Destacamos que o objetivo no momento reside tão somente em destacar alguns traços comparativos com o modelo brasileiro, o qual começa a se delinear.

O primeiro deles será o settlement norte-americano da Regra 23 das Federal Rules of Civil Procedure, que sofreu alterações importantes em dezembro de 2018. Essas alterações, e em especial uma delas, nos parece relevantíssima para se traçar um formato adequado de consenso na esfera coletiva em geral, aplicada aos acordos realizados em IRDR. 
O outro instrumento de direito comparado se refere ao acordo no Musterverfahren alemão, cuja previsão veio expressa na KapMuG - Kapitalanleger-Musterverfahrensgesetz após o advento da reforma de 2012.

O objetivo ao trazer esses dois institutos do direito estrangeiro, como já ressaltado, consiste em lançar luzes a um possível formato ainda inexistente no Brasil, mas que pode ser viabilizado num futuro próximo.

Pois bem. É cediço que o acordo consiste no resultado mais propenso de ser obtido nos Estados Unidos. ${ }^{22}$ Estudos revelam que $90 \%$ dos processos americanos são extintos por negociações entre as partes, isso sem cogitar as contendas solucionadas pela via extrajudicial, independentemente da propositura de ação. ${ }^{23}$

O fomento à consensualidade também consiste em prática recorrente nas ações coletivas, mas com uma distinção: para que um acordo coletivo vincule os indivíduos que não tiveram o seu day in court, ${ }^{24}$ o Poder Judiciário deverá aprová-lo, de modo que só surtirá efeitos após a homologação judicial. ${ }^{25}$

O acordo deverá ser justo, adequado e razoável. Conquanto sejam conceitos jurídicos indeterminados, o Manual for Complex Litigation, correspondente a uma compilação de orientações jurisprudenciais às Cortes Federais, estabelece algumas balizas de aplicação. ${ }^{26}$ Em resumo, a adequação, a justiça ou a razoabilidade do settlement consiste na ponderação entre os benefícios do acordo com as vantagens obtidas em eventual demanda coletiva, exame a ser realizado casuisticamente pelo juiz.

\footnotetext{
${ }^{22}$ HENSLER, Deborah R. A Glass half full, a glass half empty: the use of alternative dispute resolution in mass personal injury litigation, in 73 Texas Law Review 1587, June 1995, p. 9.

${ }^{23}$ GIDI, Antonio. A Class Action como instrumento de tutela coletiva de direitos. Ob. cit., pp. 306/330.

${ }^{24}$ NAGAREDA, Richard A. Mass Tort Litigation in a World of Settlement. Chicago: Oxford University, 2007.

${ }^{25} \mathrm{O}$ procedimento de aprovação da negociação atende quatro importantes etapas: i) apreciação preliminar dos termos da proposta; ii) notificação dos membros ausentes de acordo com as regras de notificação do tipo de class action que se pretende extinguir; iii) notificação de órgãos públicos dos planos estadual e federal; iv) designação de audiência pública para aprovação final da proposta (settlement hearing) V. GIDI, Antonio. A Class Action como instrumento de tutela coletiva de direitos. Ob. cit., p. 362.

${ }^{26}$ Manual for Complex Litigation, 2004, p.351, disponível em https://www.cand.uscourts.gov/complexlitmanual, acesso em 20 de março de 2019.
} 
Sobre a notificação dos membros ausentes, que se encontra prevista na subdivisão (e) (1) da regra 23, esta se refere a um instrumento imprescindível para a vinculação da classe aos termos do acordo.

Uma das alterações com a reforma de dezembro de 2018 corresponde justamente às formas de notificação, que a partir de então se atribuirá ênfase aos meios eletrônicos. O intuito é, além de levar ao conhecimento da classe afetada por aquela violação a direito de origem comum, convidar as partes interessadas para participarem da audiência pública (fairness hearing) de aprovação da proposta de natureza coletiva, de forma a auxiliar a análise de sua adequação e viabilidade.

Assim a regra 23 (e)(1) traz a previsão do que se denomina de notificação razoável (fair notice), e antes da reforma de 2018 atribuía ao magistrado, de modo bastante vago, amplas prerrogativas para decidir o modo de notificação que reputar como o mais adequado. O fato é que, historicamente, a imprecisão da norma levava as partes a usarem o correio tradicional para fornecer avisos aos membros. Era um método lento, ineficiente e mais caro. Com as novas alterações, a regra 23 se voltou para métodos mais modernos de notificação como, "os meios eletrônicos ou outros meios apropriados", conforme dispõe sua atual redação.

Após a notificação dos interessados, a proposta é analisada em audiência pública, onde são aferidos os critérios ditos acima - justiça, adequação e razoabilidade. Outra importante novidade trazida pela reforma é que a própria lei previu alguns parâmetros para analisar a presença desses critérios. ${ }^{27}$

Nas demandas sobredireitos individuais homogêneos, é pela notificação que os membros ausentes poderão exercer o seu direito de autoexclusão (right opt out), não se submetendo aos efeitos da coisa julgada coletiva. O mesmo deverá ser feito, mediante uma proposta de lege ferenda, dentro da sistemática dos acordos a serem celebrados em IRDR.

\footnotetext{
${ }^{27}$ Vejamos alguns deles: (i) analisar se os representantes da classe são representantes adequados, sem a existência de objetivos individuais e dissonantes com aqueles interesses defendidos; (ii) observar se a proposta apresentada trata os membros da classe de forma equitativa em relação um ao outro; (iii) avaliar os custos, os riscos e a demora para o julgamento da demanda, (iv) averiguar se há interesses particulares dos advogados, como por exemplo a distribuição e o momento de pagamento dos honorários advocatícios etc. Cf. John M. Barkett, Shook, Hardy \& Bacon L.L.P. The 2018 Amendments to the Federal Class Action Rule. Disponível em: <https://www.americanbar.org/content/dam/aba/administrative/litigation/materials/2017-2018/2018-sac/writtenmaterials/miami-class-actions-amendments-to-the-federal-class.pdf $>$, acesso em 24 dez./2018.
} 
Nessa perspectiva, se a causa-piloto corresponder a uma ação coletiva - observando na afetação, a preferência desta em detrimento da demanda individual -, deverá ocorrer a notificação de todos os interessados na questão de direito comum, para que assim possam exercer o seu direito de autoexclusão. Dessa maneira, aqueles que exercerem o opt out não serão abarcados pelo resultado da negociação celebrada.

Prosseguindo na análise do direito comparado, no sistema alemão a possibilidade de acordo em esfera coletiva consta na Kapitalanleger-Musterverfahrensgesetz (KapMuG), que adveio em 2005 para conflitos relacionados a área de mercado de capitais. Em 28 de Junho de 2012, o diploma em destaque sofreu alterações significativas, como, por exemplo, a previsão de uma plataforma eletrônica para a gestão da ferramenta, bem como a possibilidade de celebração do o acordo coletivo, o qual não estava previsto na versão originária da KapMuG.

Em linhas gerais, o novo estatuto preceitua que o juiz homologará o acordo quando um número mínimo de interessados aderir à proposta após a oportunidade de se manifestarem individualmente. Após a aprovação em juízo, o acordo celebrado vinculará todos os interessados, a exceção daqueles que exercerem a autoexclusão (opt out) no prazo de 30 dias a contar de necessária notificação formal individualizada. ${ }^{28}$

A propósito, se $30 \%$ ou mais dos interessados realizarem o opt out, o acordo não será homologado judicialmente, sendo certo que se isso não ocorrer, a negociação coletiva abrangerá todos os processos pendentes naquele momento. Contudo, a negociação não irá produzir eficácia erga omnes, isto é, não produzirá eficácia para os casos futuros ou para aqueles interessados que não tiveram suas demandas envolvidas no processamento do procedimento modelo. ${ }^{29}$

Em virtude dessa recente alteração, não se conhece de estudos estatísticos que possam demonstrar o grau de êxito da novel reforma. Certamente, a norma não é o ponto de chegada, mas o estágio de partida para a mudança jurídica e cultural almejada.

\footnotetext{
28 Apontamento esclarecedor: Michael Weigel; Arnold Porter, disponível em: https://www.expertguides.com/articles/collective-redress-in-germany/collec14, acesso em 04 jun 2018.

29 v. Kapitalanleger-Musterverfahrensgesetz - KapMuG - (versão em inglês): http://www.processoscoletivos.com.br/images/PDFs/Brazilian_Class_Actions/KapitalanlegerMusterverfahrensgesetz-KapMuG_English_version.pdf
} 
No ordenamento brasileiro não há previsão a esse respeito, o que não deve inviabilizar a sua prática. Partindo da premissa de que o IRDR compõe relevante técnica de coletivização de demandas, podemos nos valer de alguns critérios aplicadosno direito estrangeiro. .

O modelo alemão, assim como o norte-americano, podem servir como fontes de inspiração sobre a necessidade de ampla participação dos interessados, necessariamente com audiências públicas prévias à homologação da proposta em juízo. Nesse contexto, a notificação ampla e individualizada é imperiosa para que seja oportunizada a escolha de se vincular ou não ao acordo.

Perceba-se que se for processado normalmente, o IRDR não permite essa escolha aos interessados na formação da tese jurídica; contudo o acordo assim o permitirá. A faculdade de autovinculação à negociação partirá, portanto, de cada interessado.

Parece-nos que o embrião do tema no Brasil foi introduzido pela Lei de Mediação (Lei 13.140/2015), no artigo 35. Ao se verificar a redação normativa, que autoriza a transação por adesão nas controvérsias jurídicas envolvendo a administração pública federal direta e suas autarquias e fundações, podemos enxergar que o legislador adotou a necessidade de autovinculação expressa, isto é: se o interessado optar pela submissão à eficácia do acordo, deverá se manifestar de modo inequívoco.

Ao trazer a matéria ao âmbito do IRDR, seria razoável observar a técnica do opt in para os interessados que não possuam demandas pendentes de aplicação da tese jurídica e o opt out aos que estejam no aguardo da decisão da questão comum.

Dessa forma, realizada a intimação individual de cada demandante atual, a omissão em prazo razoável falaria pela submissão aos termos do acordo, desde que um número razoável de litigantes não se manifeste contra os termos da proposta, como, por exemplo, ocorre no direito alemão, que leva em consideração o índice de 30\% de rejeição máxima.

Portanto, a aceitação mínima aos termos da proposta é de 70\%. Se não for respeitada, o acordo sinalizará a sua inviabilidade, sendo certo que a homologação judicial nesse caso se faz necessária e ali será avaliada a legitimidade da proposta. Já para aqueles que ainda não ajuizaram as suas demandas, a vinculação requer expressa manifestação, assim como prevê o 
artigo 35 da Lei de Mediação e seus parágrafos. Inclusive, pensamos ser possível a aplicação da inteligência do $\S 4^{\circ}$, no sentido de que a adesão expressa implicará renúncia do interessado ao direito sobre o qual se fundamenta a ação no que tange aos pontos compreendidos, segundo a lei na resolução administrativa, e aqui, nos termos da proposta.

Por fim, podemos destacar que a possibilidade de acordo em demandas sobre direitos individuais homogêneos foi corroborada, por exemplo, pela resolução da questão versada na ADPF 165 sobre os planos econômicos. Nos termos do entendimento firmado pelo STF, a homologação do acordo não pressupõe a chancela de teses defendidas pelas partes, mas apenas os exames de legitimidade, validade e legalidade das transações de natureza patrimonial. ${ }^{30}$

\section{NOTAS DE CONCLUSÃO: UMA NOVA MIRADA PARA O FUTURO}

O estudo objetivou romper com o falso dogma de que as instâncias de consenso seriam diametralmente opostas à ratio essendi do Incidente de Resolução de Demandas Repetitivas (IRDR).

Vimos que, a princípio, quando houver negociação na causa-piloto a respeito da questão comum de direito, parece que não haverá submissão ao precedente judicial obrigatório em relação àqueles que aderiram à proposta. Na verdade, reconhecer a inaplicabilidade da tese para os interessados e aderentes do acordo judicial, nessas situações, não significa desconsiderar a importância da vinculatividade obrigatória dos precedentes judiciais, mas encontrar um ponto de equilíbrio entre essa relevante conquista, alinhada à efetivação de outros Direitos Fundamentais, como o autorregramento dos cidadãos, enquanto corolário da dignidade humana.

É importante esclarecer que os acordos em IRDR poderão ocorrer de diversas formas. As consequências sobre a possibilidade de vinculação dos interessados quanto aos termos da negociação e suscetibilidade ou não dos celebrantes ao precedente judicial formado irão depender do tipo de acordo celebrado. Quando nos referimos ao acordo sobre a questão comum

\footnotetext{
${ }^{30}$ V. Decisão na íntegra: http://www.stf.jus.br/arquivo/cms/noticiaNoticiaStf/anexo/Relatorio_ADPF_165.pdf, acesso em 15 de fevereiro de 2019.
} 
de direito, sustentamos que o ideal é que sua celebração seja firmada no processo paradigma, pelas razões expostas ao longo do texto.

No entanto, vimos que há possibilidade de que negociações também sejam realizadas nos processos que aguardam a formação e a aplicação da tese, já que aqueles acordos podem versar sobre apenas parte da questão comum de direito, sobre matéria não abarcada pelo incidente e, inclusive, corresponder a ajustes de natureza unicamente processual. Tendo em vista essas possíveis derivações de negociações em IRDR, focalizamos atenção principal em demonstrar a real possibilidade do consenso nesta sede, o que não representa incompatibilidade com o instituto.

De fato, o legislador deixou passar boa oportunidade para positivar a matéria no CPC. Todavia, o certo é que a inexistência de previsão normativa a esse respeito não encerra um impeditivo de sua prática, pelo contrário.

A leitura sistemática do Direito Processual Civil contemporâneo aponta para o estímulo de soluções autocompositivas e retomada do grau satisfatório de autonomia pelos indivíduos. Além do reconhecimento da possibilidade de negociação no Incidente de Resolução de Demandas Repetitivas, a urgência do tema se impõe em como estruturar e efetivar essa prática.

Uma mirada para o futuro indica que a adesão significativa à negociação no IRDR resultará da proposta mais vantajosa para autor e réu, a depender do tipo de acordo intentado. Caso não haja atrativo em se acordar, menor será o grau de adesão e, consequentemente, mais tênue será o estímulo a fim de que o réu ofereça maiores vantagens.

Assim, o magistrado poderá compreender que a proposta não será suficientemente legítima, porquanto poucos interessados a ela anuíram. Os caminhos, nesse caso, serão de duas ordens: ou a não homologação, ou os limitados efeitos produzidos pelo ajuste, de sorte que pouco ou nada contribuirá ao aprimoramento do sistema jurisdicional.

Nesse passo, parece ser fundamental examinar as consequências de uma decisão judicial possivelmente alcançada em cotejo com a proposta de negociação em sede de Incidente de 
Resolução de Demandas Repetitivas, caso o acordo seja sobre a matéria alvo do incidente ou ao menos de parte dela. ${ }^{31}$

Essa é uma conclusão que podemos extrair do próprio settlement norte-americano, no qual a regularidade da proposta é averiguada pelo Poder Judiciário ao ser conjugada com os possíveis resultados de uma decisão proferida. Trata-se de uma importante premissa a ser aproveitada desse modelo comparado exposto no texto.

Assim, o melhor acordo será aquele que contiver o máximo de aproveitamento (benefício) para ambas as partes pelo menor custo possível. ${ }^{32}$ Isso depende da confluência de diversos fatores (não apenas jurídicos) e que devem ser examinados e ponderados pela comunidade de pessoas atingidas pelos efeitos do que vier a ser avençado, observadas as circunstâncias específicas do caso concreto. Em qualquer cenário, é certo que não podemos nos esquecer dos impactos econômicos e sociais, para cada indivíduo e também para toda a coletividade. ${ }^{33}$

\section{REREFÊNCIAS BIBLIOGRÁFICAS}

CADIET, Loïc. Le spectre de la société contentieuse. Droit civil, procédure, linguistique juridique. Écrits en Hommage a Gérard Cornu. Textes réunis et publiés par Jean Beauchard et Pierre Couvrat. Paris: P.U.F, 1994.

CARPI, Federico. Introduzione. Rivista Trimestrale di Diritto e Procedura Civile. Numero speciale: accordi di parti e processo. Milano: Giuffrè, 2008.

\footnotetext{
${ }^{31}$ BABCOCK, Linda; LOEWENSTEIN, George. "Explaining Bargaining Impasse: The Role of Self-Serving Biases" Journal of Economic Perspectives, Volume 11, n. 1, 1997.

${ }^{32}$ KAPLOW, Louis. Information and the Aim of Adjudication: Truth or Consequences? Stanford Law Review, v. 67, n. 6, 2015.

${ }^{33} \mathrm{O}$ formato processual mais estratégico, conforme foi mencionado no presente estudo, encontra-se alinhado com as bases de aplicação da Análise Econômica do Direito. Em razão da densidade que o tema exige, este será exposto com maiores detalhes em um próximo trabalho. Para o presente momento, registramos que a análise dos acordos pode observada em: SHAVELL, Steven. Foundations of Economic Analysis of Law. Cambridge: Harvard University Press, 2004; BAR-GILL, Oren, The Evolution and Persistence of Optimism in Litigation, Oct., 2006. The Journal of Law, Economics, and Organization, Vol. 22, Issue 2, pp. 490-507, 2006; FRIEDMAN, Ezra; WICKELGREN, Abraham L. "No Free Lunch: How Settlement Can Reduce the Legal System's Ability to Induce Efficient Behavior". In: 61 SMU Law Review 1.355, 2008. CALABRESI, Guido. The Future of Law and Economics. New Heaven, CT: Yale University, 2016; COASE, Ronald. The Problem of Social Costs. Journal of Law and Economics, v. 3, out. 1960; KAPLOW, Louis; SHAVELL, Steven. Fairness Versus Welfare. Harvard Law Review, v. 114, n. 4, fev. 2001; POSNER, Richard. Divergent Paths: The Academy and Judiciary. Cambridge, MA: Harvard University, 2016; POSNER, Richard. Economic Analysis of Law. 8. ed. New York: Aspen, 2011.
} 
DIDIER JR., Fredie; ZANETI JR., Hermes. Justiça multiportas e tutela constitucional adequada: autocomposição em direitos coletivos. ZANETI JR., Hermes; CABRAL, Trícia Xavier Navarro (Coord.). Justiça multiportas: mediação, conciliação, arbitragem e outros meios de solução adequada para conflitos. Coleção grandes temas do novo CPC. Coordenação geral: Fredie Didier Jr. Salvador: Juspodivm, 2017.

FRIEDENTHAL, Jack H.; KANE, Mary Kay; MILLER, Arthur R. Civil Procedure. Fourth Edition, Hornbook Series, St. Paul: Thomson West.

GAVRONSKI, Alexandre Amaral. Autocomposição no novo CPC e nas ações coletivas. ZANETI JR., Hermes (Coord.) Processo Coletivo. Coleção repercussões do novo CPC. Coordenador geral: Fredie Didier Jr. Salvador: Juspodivm, 2016.

GIANNINI, Leandro J. Transacción y mediación en los procesos colectivos. São Paulo: Revista dos Tribunais, 2011. Revista de Processo, vol. 201, nov/2011, p. 149-199.

GIDI, Antonio. A Class Action como instrumento de tutela coletiva de direitos. São Paulo: Revista dos Tribunais, 2007.

GRECO, Leonardo. Instituições de processo civil - Introdução ao direito processual civil, vol.01, 5. ed. Rio de Janeiro: Forense, 2015.

GUINCHARD, Serge et al. Droit processuel: droits fondamentaux du procès, 8.ed. Paris: Dalloz, 2015, Section 1; Section 2 et Section 3.

HENSLER, Deborah R. A Glass half full, a glass half empty: the use of alternative dispute resolution in mass personal injury litigation. In: 73 Texas Law Review 1587, Jun./1995.

Manual for Complex Litigation, 2004. Disponível em: https://public.resource.org/scribd/8763868.pdf, acesso em 17 jun 2018.

MCGOVERN, Francis E. Settlement of Mass Torts in a Federal System. In: Wake Forest Law Review, v. 36, 2001.

MENDES, Aluisio Gonçalves de Castro. Incidente de Resolução de Demandas Repetitivas. Sistematização, análise e interpretação do novo instituto processual. Rio de Janeiro: Forense, 2018.

MOREIRA, José Carlos Barbosa. Tutela jurisdicional dos interesses coletivos ou difusos. Temas de Direitos Processual Civil - 3. série. São Paulo: Saraiva, 1984, p. 195-197;

MOREIRA, José Carlos Barbosa. A ação popular no Direito Brasileiro, como instrumento de tutela jurisdicional dos chamados interesses difusos. Revista de Processo, São Paulo, n. 28, p. 7-19, out./dez. 1982.

MULLER, Ivone. Le contrat judiciaire en droit privé. These pour le Doctorat en Droit. Paris: Université de Paris I Panthéon-Sorbonne, 1995. 
PAUMGARTTEN, Michele. Os desafios para a integração das práticas conciliatórias no novo processo civil. In: Revista de Processo, n. 247. São Paulo: Revista dos Tribunais, 2015.

PICARDI, Nicola. La giurisdizione all'alba del terzo millennio. Dialettica, Diritto e Processo. A cura di Alessandro Guiliani e Nicola Picardi, v.3. Milano: Giuffrè Editore, 2007.

PINHO, Humberto Dalla Bernardina de; VIDAL, Ludmilla Camacho Duarte. Primeiras Reflexões sobre os Impactos do novo CPC e da Lei de Mediação no Compromisso de Ajustamento de Conduta. In: Revista de Processo, vol. 256. São Paulo: Revista do Tribunais, 2016.

PINHO, Humberto Dalla Bernardina de; VIDAL, Ludmilla Camacho Duarte. La nouvelle configuration des accords collectifs du droit brésilien. In: International Journal of Procedural Law, v. 08/01, 2018, pp.125-132.

RODRIGUES, Roberto de Aragão Ribeiro. Os limites do compromisso de ajustamento de conduta extrajudicial na tutela dos direitos transindividuais. In: Revista Eletrônica de Direito Processual, vol. IX, p. 697-733. Disponível em http://www.redp.com.br

VIDAL, Ludmilla Camacho Duarte. Convenções Processuais no paradigma do Processo Civil contemporâneo. Rio de Janeiro: Gramma Editora, 2017.

WEBER, Mark C. A Consent-Based Approach to Class Action Settlement: Improving Amchem Products, Inc. v. Windsor. In: Ohio State Law Journal, v. 59. n. 4, 1998.

Data de submissão: 20/08/2019

Data de Aceite: 03/12/2019 